\title{
Ensino de geografia: o estudo do município nos anos iniciais
}

\author{
Geography teaching: study of the municipality in the years early
}

\section{Mizael Dornelles}

\section{Erica Karnopp}

Univerisdade de Santa Cruz do Sul - Unisc - Santa Cruz do Sul - Rio Grande do Sul - Argentina

Resumo: O artigo trata do ensino de Geografia através do estudo do município nos anos iniciais. Tem como objetivo verificar a metodologia do ensino de Geografia e o município nos anos iniciais. Para tanto, foram entrevistados professores e estudantes do quarto ano do ensino fundamental de escolas públicas municipais e estaduais e escolas privadas nos municípios de Santa Cruz do Sul-RS, Rio Pardo-RS e Pantano Grande-RS. Como resultado, procuramos oferecer algumas sugestões e subsídios na intenção de auxiliar e consequentemente melhorar o estudo do município nos anos iniciais. As considerações finais trazem apontamentos para uma melhor construção do estudo do município e ainda, indicações de referências no Portal do IBGE que podem suprir significativa parcela da demanda de materiais.

Palavras-chave: Ensino de Geografia. Estudo do município. Anos iniciais.

\begin{abstract}
The article deals with the geography teaching through municipality study in the early years. The objective was to verify the teaching methodology of Geography and the municipality in the early years. For this, we interviewed teachers and students of the fourth year of primary education in public schools and private schools in Santa Cruz do Sul-RS, Rio Pardo-RS e Pantano Grande-RS. As a result, we try to offer some suggestions and subsidies in an attempt to assist and therefore improve the study of the municipality in the early years. The conclusion makes considerations for better construction of the municipality study also shows indications of references in the IBGE website that can supply significant part by the demand for materials.
\end{abstract}

Keywords: Geography Teaching; Study of the municipality; Early years.. 


\section{Introdução}

Um grande desafio no ensino da Geografia é a formação de um cidadão crítico. Esta tarefa requer muita dedicação e deve ser pensada e multiplicada na alfabetização espacial, a partir de professores não formados em Geografia. Os Planos Curriculares Nacionais (BRASIL, 1997), recomendam para o ensino de Geografia nos anos iniciais as categorias de lugar, paisagem e território. Porém, a não formação dentro da Geografia limita o emprego destas categorias e complica a utilização de recursos auxiliares. Com isso, livros didáticos abordam categorias geográficas que proporcionam reflexões oriundas de pesquisas, muitas vezes complexas para profissionais da Geografia, e os professores primários, formados em outras áreas se esmeram para aproximar a realidade à sala de aula. A falta de material reunido sobre o município acaba dificultando ainda mais esse desafio.

O município é estudado, notadamente, nos anos iniciais, do primeiro ao quinto ano do ensino fundamental de nove anos. A ênfase ao município é dada no $4^{\circ}$ ano, através da categoria de lugar. A categoria de lugar permite ao professor trabalhar em Geografia o espaço cotidiano, sem limitações dadas por uma definição política e administrativa de bairro ou distrito. Entretanto, Castrogiovanni (2008), é categórico ao destacar pesquisas que comprovam que muitos professores dos anos iniciais não foram alfabetizados em Geografia e são responsáveis por uma constante confusão teórico-metodológica entre Geografia, História, Sociologia e Filosofia. Os significados muitas vezes incompreendidos pelos professores aparecem nulos para os estudantes, além do afastamento da escola com a vida e o cotidiano do estudante. "É urgente teorizar a vida, para que o aluno possa compreendê-la e representála melhor e, portanto, viver em busca de seus interesses" (CASTROGIOVANNI, 2008, p.15).

Nesse sentido, tivemos a proposição de analisar a prática pedagógica dos professores sobre 0 ensino de Geografia e o estudo do município. Em linhas gerais, verificar a metodologia de estudo do município em Geografia nos anos iniciais, bem como identificar os recursos e limitações presentes, junto a professores e estudantes. A razão de tal investigação partiu de debates, na disciplina de Prática em Geografia do Curso de Geografia da UNISC, sobre as agruras de estudar o município no ensino fundamental.

Este artigo, inicialmente apresenta alguns esclarecimentos relativos à alfabetização espacial, a metodologia de coleta de dados e entrevistas e dos municípios e escolas visitadas. $\mathrm{Na}$ sequência, realizamos uma descrição e análise dos resultados verificados e identificados nos levantamentos de campo. Por último, nas considerações finais, sinalizamos para alternativas que visam melhorar o estudo do município em Geografia.

\section{Primeiros esclarecimentos}

A alfabetização espacial procura instruir, os estudantes dos anos iniciais, para uma leitura do espaço em suas diversas dimensões. Procuramos aplicar questionários para professores e estudantes na intenção de capturar parte desta atmosfera. Os questionários foram aplicados em escolas da rede pública municipal e estadual e escolas privadas em três municípios com características diferentes.

\subsection{A alfabetização Espacial}

Por onde devemos iniciar o ensino de Geografia para as crianças? Não há conceitos estanques na Geografia, porém, uma sugestão muito presente é através da categoria de lugar (CALLAI, 2005 e 2008; CASTROGIOVANNI, 2008; BRASIL, 1997; PONTUSCHKA, 1999; STRAFORINI, 2001).

De acordo com Castrogiovanni (2008), nos primeiros anos de escolarização deve-se trabalhar valorizando o espaço e tempo vivenciados. Isto é, a construção de noções temporais, quantificação e representação das categorias do passado, presente e futuro e caracterização de épocas. Sem impor limites, de espaço e tempo, é importante estudar movimentos amplos. Com isso, o município é um excelente laboratório para a inserção do estudante na 
Geografia. Para entender como o espaço é produzido, como as pessoas vivem e trabalham, basta dar uma volta pela cidade com olhos atentos às manifestações e materializações, ao existente e suas significações.

O estudo do município permite análises diversas e complexas que são verificadas através da vivência da realidade. Não são apresentadas informações de acontecimentos distantes onde se procura ligações, mas sim a proximidade dos elementos que expressam o mundo, presentes e perceptíveis na escala local, do município (CALLAI e ZARTH, 1988).

\begin{abstract}
Estudar o local é muito importante para o aluno, pois ali ele "conhece tudo", ele sabe o que existe, o que falta como são as pessoas, como são organizadas as atividades, como é o espaço. [...] como trabalhar o local sem considerá-lo como o "único", sem considerar que as explicações estão todas ali, sem cair no risco de isolá-lo no espaço e no tempo (CALLAI e ZARTH, 1988, p.17).
\end{abstract}

Cabe ressaltar que o município necessita ser entendido no mundo e relacionado a outras escalas como a regional e a internacional (CALLAI, 2008). Portanto, uma grande questão imposta ao ensino da Geografia, notadamente nos anos iniciais e estudo do município, são os chamados 'círculos concêntricos'. Trata-se de uma prática tradicional, onde é apresentada aos estudantes uma sequência linear do mais simples e próximo ao mais distante. Todavia, essa noção coloca-se 'débil', uma vez que, o mundo é muito mais complexo em sua dinamicidade, e não pode ser simplificado numa visão de círculos que se ampliam sucessivamente. (CALLAI, 2005).

Para Straforini (2001), vale uma analogia com o ensino da linguagem escrita. Até a década de 1980 a alfabetização na língua portuguesa ocorria pelo método sintético, como na maioria dos casos é repassada a Geografia. Primeiro aprendia-se o alfabeto dividido em vogais e consoantes, para depois juntá-las formando as sílabas, palavras e por fim o texto. Na Geografia o município, estados, grandes regiões, país e mundo. Essa concepção somente mudou quando foram apresentados estudos revelando que as crianças apresentam intensa reflexão passando por diferentes fases em sua compreensão, visto que, estas fases não precisam ser cumpridas uma a uma (STRAFORINI, 2001). Ou seja, as escalas geográficas não podem ser compreendidas como coisas únicas e isoladas.

[...] não se deve trabalhar do nível local ao mundial hierarquicamente: o espaço vivido pode não ser o real imediato, pois são muitos e variados os lugares com os quais os alunos têm contato e, sobretudo, que são capazes de pensar sobre. A compreensão de como a realidade local relaciona-se com o contexto global é um trabalho que deve ser desenvolvido durante toda a escolaridade, de modo cada vez mais abrangente, desde os ciclos iniciais. [...] Estudar a paisagem local ao longo dos primeiro e segundo ciclos é aprender a observar e a reconhecer os fenômenos que a definem e suas características; descrever, representar, comparar e construir explicações, mesmo que aproximadas e subjetivas, das relações que aí se encontram impressas e expressas (BRASIL, 1997, p.77).

O ensino de Geografia acerca do estudo do município nos anos iniciais é conteúdo significativo na construção de entendimentos básicos de identidade, história, espaço e pertencimento ao mundo. Considera o espaço em que vive o estudante e contribui para o conhecimento empírico, teórico e crítico da realidade. Como resultado, possibilita a compreensão da importância dos conteúdos geográficos nas atividades cotidianas e vinculando a disciplina com a realidade.

\subsection{Esclarecimentos metodológicos}

Diante das nossas proposições, procuramos classificar este estudo como uma investigação cujo tipo, obedece aos seguintes critérios: quanto à finalidade, básica ou fundamental; de caráter e objetivos exploratórios; procedimentos diversos; de natureza quantitativa e qualitativa; realizada em laboratório e campo (VIANA, 2001).

No intuito de melhor operacionalizar a coleta de dados e em função do curto período para isso, foi realizada uma amostragem 'não probabilística intencional', isto é, não probabilística por ter uma seleção de elementos que compõem a amostra, 
dependentes, ao menos em parte, do julgamento do pesquisador. $E$ intencional por haver um julgamento para selecionar as fontes de informação mais precisas (TRIOLA, 1999).

De acordo com essa amostragem, foram selecionados três municípios. Para tal escolha, levamos em consideração suas diferentes formações espaciais e temporais, além de sua proximidade. Da mesma forma, foram investigadas, em cada um desses municípios, duas instituições públicas (uma estadual e uma municipal) e uma privada. Com isso, elegemos os municípios de Santa Cruz do Sul-RS, Rio Pardo-RS e Pantano Grande-RS.

Os sujeitos da pesquisa foram professores e estudantes do Ensino Fundamental do $4^{\circ}$ ano. Os instrumentos de coleta foram dois questionários, um aplicado aos professores e outro aos estudantes. Os professores responderam a 6 questões fechadas e 4 questões abertas e os estudantes a 3 questões fechadas e 2 questões abertas.
No que diz respeito ao processo, os questionários foram aplicados aos professores em sala separada, ou quando junto aos estudantes, depois deles serem questionados. O questionário aos estudantes foi aplicado na presença do professor em sala de aula mediante leitura em grupo e esclarecimentos. Grifamos para os estudantes que não havia respostas certas, nem erradas, e que os estudantes somente deveriam escrever e não falar as respostas. Também foi solicitado que não consultassem nenhum tipo de material, professor ou colega.

\subsubsection{Os municípios e as escolas selecionados}

Procuramos aqui, em poucas palavras, caracterizar as diferenças nos três municípios selecionados e ilustrar as escolas visitadas. Não entraremos em detalhes, visto que temos 0 compromisso de preservar o nome das escolas. $O$ mapa mostra onde estão situados os municípios selecionados.

Mapa - Municípios selecionados

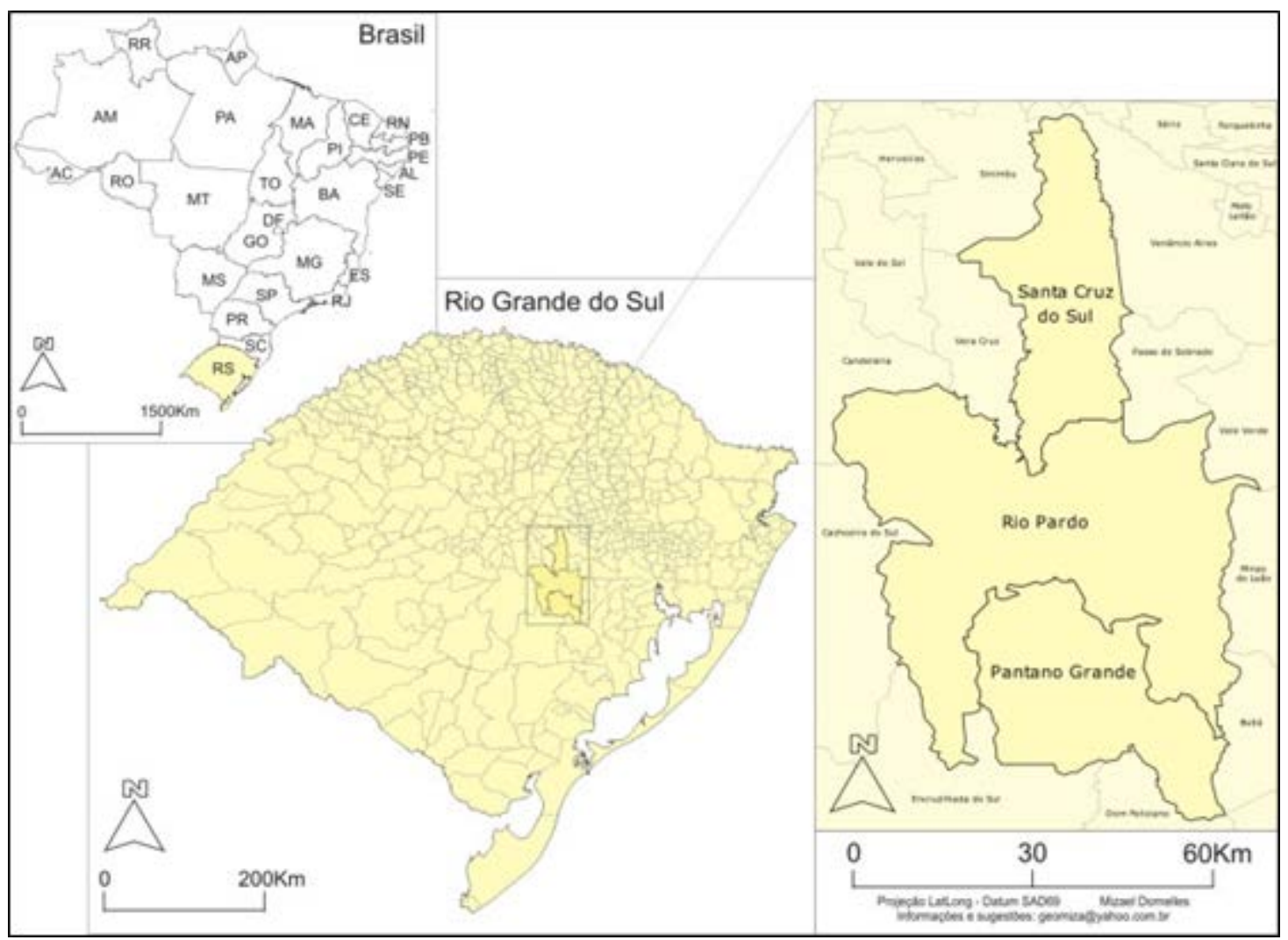

Fonte: IBGE, 2012. Elaborado por Mizael Dornelles. 
O município de Santa Cruz do Sul-RS tem sua origem com a ocupação do território por imigrantes naturais da Alemanha com a criação de um núcleo colonial pelo governo da Província do RS, em 1849. Emancipado de Rio Pardo em 1877, sua história está atrelada a produção e processamento de tabaco e cigarros. No período atual, o espaço urbano local configura um dos mais importantes centros de processamento industrial de tabaco em escala mundial (SILVEIRA, 2003). Conforme o IBGE (2015), o município tinha estimada uma população total de 126.084 habitantes em 2015; taxa de analfabetismo de 4,71 \%; PIB de R \$ 4,5 bilhões; e PIB per capita de $\mathrm{R} \$ 37.132,27$. As três escolas de Santa Cruz do Sul estão situadas em bairros distintos. Nenhuma no centro da cidade e atendem, a estudantes de condições financeiras dispares, mas não levadas ao extremo. Uma escola é de Educação Básica e duas de Ensino Fundamental.

A formação da primeira povoação de Rio Pardo-RS se desenvolveu no entorno do forte "Jesus, Maria, José do Rio Pardo" (construído em 1752), com importante contribuição na constituição do território do RS diante dos espanhóis. Ao lado de Porto Alegre, Rio Grande e Santo Antônio da Patrulha, é um dos quatro primeiros municípios do RS. Até o final do século XIX Rio Pardo mantinha uma importante função na economia do Estado. Porém, sucessivos acontecimentos como a Revolução Farroupilha, contínuos desmembramentos de território e o fim do movimento do porto fluvial fizeram declinar a boa situação do município (VOGT e ROMERO, 2010). A população total estimada em 2015 foi 38.934 habitantes; taxa de analfabetismo de 11,24\%; PIB de R\$ 474,8 milhões (IBGE, 2015); e o PIB per capita de $\mathrm{R} \$ 12.458,58$. Das escolas selecionadas, uma atende na periferia uma comunidade carente. As outras duas escolas estão situadas no centro urbano. Neste caso, há um distanciamento significativo nas condições financeiras dos estudantes, de uma escola para outra. Duas escolas são de Educação Básica e uma de Ensino Fundamental.

A partir de 1930 a exploração de lavouras de arroz, calcário/caulim trouxeram um pequeno contingente de pessoas a Pântano Grande. Na década de 1950 com a construção da rodovia federal, BR-290, e posteriormente em meados de 1970, BR471, outra, perpendicular, assinala um período de investimentos em infraestrutura e serviços. Com a intensificação no tráfego associada ao desenvolvimento local, à população aumentou e em 1989 deixou de integrar a Rio Pardo (IBGE, 2009). A população total estimada em 2015 era de 9.932 habitantes; taxa de analfabetismo de 13,75\%; PIB de R\$ 145,1 milhões (IBGE, 2015); PIB per capita de $\mathrm{R} \$ 14.277,00$. Ambas as escolas selecionadas estão localizadas no centro. Uma de Ensino Fundamental e outra de Educação Básica. Não há diferenças consideráveis de condição financeira entre os estudantes.

\section{Descrição e análise dos resultados}

As informações a seguir trazem os resultados dos questionários aplicados aos professores e estudantes. Procuramos dar ênfase a análise dos dados gerais ao estratificarmos por município ou tipo de escola, ou seja, correspondem a 13 turmas entrevistadas nos três municípios.

\subsection{Professores}

Foram entrevistados 13 professores, todas mulheres, com tempo de serviço diferente: 4 atuavam com até 4 anos no ensino fundamental séries/anos iniciais, 1 entre 5 a 9 anos e 8 com 10 anos ou mais. No que diz respeito à formação destas professoras, todas cursaram magistério, porém, 5 estavam em fase de conclusão da graduação; 4 tinham pósgraduação Lato Senso, relacionadas a Educação Básica. Com graduação em Pedagogia eram 9 e em outras áreas do conhecimento 4.

As Professoras foram questionadas sobre como as aulas de Geografia são organizadas. As respostas possibilitaram uma classificação em 4 maneiras diferentes. Há um equilíbrio para os quantitativos de três maneiras, havendo somente uma professora mais rígida e disciplinada quanto ao dia e horário. Convém destacar que todas as escolas 
deixam a critério de cada professor tal organização. A tabela 1 mostra a opção de cada Professora em suas respectivas turmas na organização das aulas de Geografia.

Tabela 1. Organização das aulas de Geografia

\begin{tabular}{lc}
\hline \multicolumn{1}{c}{ Maneira } & $\begin{array}{c}\mathbf{N}^{\mathbf{2}} \\
\text { professoras }\end{array}$ \\
\hline $\begin{array}{l}\text { Sempre no mesmo dia e horário } \\
\text { Uma vez por semana sempre no }\end{array}$ & 1 \\
$\begin{array}{l}\text { mesmo dia } \\
\text { Uma ou mais vezes por semana (não }\end{array}$ & 4 \\
$\begin{array}{l}\text { no mesmo dia) } \\
\text { Outro* }\end{array}$ & 4 \\
\hline Total & 4 \\
\hline
\end{tabular}

* Trabalham a Geografia sem uma regularidade não respeitando um horário pré-estabelecido.

Fonte: Resultados da pesquisa de campo. Elaborado pelos autores.

Em linhas gerais, as professoras entrevistadas, procuram estudar o município relacionando a formação e fatos históricos às estruturas físicas com pouco enfoque em suas significações espaciais. As ideias mais abstratas fazem parte, agora de aspectos históricos. Durante as aulas de Geografia, procuram tratar mais da paisagem, do concreto, que pode ser facilmente descrito e observado. As relações como produção e reprodução do espaço não são debatidas. O enfoque é físico e principalmente cartográfico, em algumas situações a Geografia foi concebida como prática e pouco teórica.

Destas Professoras, somente uma procura trabalhar da escala local para a mundial. Isto é, quase unanimidade entre as professoras pesquisadas, iniciar o estudo do município da escala mundial para a local. Uma professora procura não trabalhar 0 mundo e parte do regional para o município.

Houve dificuldades em responder como percebem o conceito de lugar. A ideia principal comentada estava relacionada ao espaço, meio de vivência, ocupado, onde estamos agora, também como um espaço dentro de outro. Cabe esclarecer que o conceito de lugar, de acordo com BRASIL (1997. p. 76)

[...] a categoria de lugar traduz os espaços com os quais as pessoas têm vínculos mais afetivos e subjetivos que racionais e objetivos: uma praça que se brinca desde menino; a janela onde se vê a rua; o alto de uma colina, de onde se avista a cidade. O lugar é onde estão as referências pessoais e o sistema de valores que direcionam as diferentes formas de perceber e constituir a paisagem e 0 espaço geográfico.

Neste sentido, as limitações e dificuldades apontadas para estudar o município estavam relacionadas principalmente a falta de mapas municipais, 8 professoras lembraram este item. Também foram destacadas a falta material didático e paradidático por 4 professoras; além da falta de referências, literatura e indicadores atualizados sobre o município, 3 professoras; falta de recursos e apoio para excursões de campo, 3 professoras. Duas professoras alegaram ainda, insegurança para trabalhar alguns assuntos relacionados a Geografia devido a complexidade dos conceitos e outras duas disseram não haver dificuldade ou limitação nenhuma em estudar o município em Geografia. Segue, em tópicos, o que cada Professora indicou como pendente:

- Mapas do município;

- Mapas do município sobre hidrografia, relevo e usos do solo;

- Mapas do município, material didático sobre o município;

- Mapas do município, referências sobre o município, material didático sobre o município;

- Mapas do município e indicadores atualizados, material didático sobre 0 município, insegurança para alguns assuntos;

- Mapas do município, materiais paradidáticos sobre o município, referências e um órgão a quem recorrer, para encontrar ou reunir informações sobre o município;

- Mapas do município, recursos e apoio para excursões de campo (para área rural), insegurança para alguns assuntos;

- Mapas do município, recursos e apoio para excursões de campo; 
- Recursos e apoio para excursões de campo;

- Referências sobre o município (fontes confiáveis)

- Fazer com que os estudantes compreendam conceitos (rural, urbano);

- Não há dificuldades;

- Não há dificuldades.

Diante de tais respostas acreditamos que a construção de um atlas municipal seria relevante, e supriria significativa parcela destas carências, mas não cobriria a todas.

As professoras ainda foram questionadas sobre o material didático disponível. Segundo 3 professoras, não havia nenhum material didático, em particular, que tratava do município em que atuava. Já outras 6 professoras, que consideraram o material elaborado por elas, através de buscas e pesquisas próprias, a resposta foi que o material didático sobre o município é limitado. Outras 4 professoras ainda disseram ser suficiente o material sobre o município. As sugestões, aqui, foram semelhantes as do questionamento acima. Vale uma ressalva, referente à carência e muitos pedidos de mapas do município/distritos/sedes, bem como, referências para informações atualizadas.

Em seguida, foi solicitado que as professoras fizessem uma auto avaliação dos seus conhecimentos em Geografia, enquanto professoras do ensino fundamental anos iniciais. Para trabalhar o município em Geografia, todas se consideraram capacitadas, porém em diferentes níveis. As professoras que classificaram seus conhecimentos relativos à disciplina como limitados, indicam carências em sua formação e sugeriram cursos e oficinas específicos para a área. As professoras que declararam conhecimentos suficientes apontaram maior necessidade de oficinas com atividades práticas. As professoras com conhecimento excelente, mostraram interesse em uma formação sobre o município.

Como último questionamento, procuramos saber do acesso a verbas junto à escola para excursões de campo e atividades diversas. A seletividade a partir da condição financeira, segundo a situação administrativa de cada escola e cada estudante é relevante ao extremo. As escolas estaduais não têm condição nenhuma de fomentar este tipo de atividade, somente se cada um contribuir com uma quantia, o que excluiria significativa parcela de estudantes. As escolas municipais, já conseguem algum transporte através da Prefeitura Municipal e Secretarias de Educação, porém não muito mais que isso. Numa outra realidade, as escolas particulares em parceria com os familiares dos estudantes arrecadam fundos, cobrindo inclusive as bolsas dos estudantes mais carentes, ocorrendo assim à participação de todos. Para a realização de excursões de campo, foi lembrada a existência de muitas dúvidas e certa hesitação, por parte da escola e dos pais dos estudantes. Em outras palavras, a importância de tal atividade sempre envolve tantos questionamentos, desde a falta de apoio e necessidade de justificativas para além do conteúdo, até elementos básicos como os objetivos a serem alcançados. O mesmo ocorre com outras atividades como elaboração e construção de feiras de Geografia ou eventos relacionados há dias festivos.

\subsection{Os estudantes}

As turmas tinham em média 22 estudantes. Somente uma escola mostrou preocupação em trabalhar o município na continuidade do processo de aprendizagem, deixando assim, a critério das metodologias aplicadas pelo professor rever e ou retrabalhar o município, segundo as suas necessidades.

Ao todo, 293 crianças do $4^{\circ}$ ano responderam ao questionário. Dessas, quando questionadas se conheciam o município 270 (92\%) marcaram que sim e 19 (6,5\%) que não. Porém, 96 (32,8\%) não souberam, em seguida, escrever o nome do município. Assim, 197 (67,2\%) escreveram corretamente o nome do município, 65 (22,2\%) deixaram em branco ou confundiram com rua, bairro e $31(10,6 \%)$ confundiram o Estado com o Município. 
Introduzindo a ideia da relação cidade e campo, os estudantes foram questionados se habitavam meio urbano ou o meio rural. Cabe ressaltar, todos os estabelecimentos de ensino visitados eram na zona urbana. A maioria dos estudantes, 218 (74,4\%), responderam que habitavam a meio urbano, $61(20,8 \%)$ o meio rural e 14 (4,8\%) deixaram em branco.

Em seguida os estudantes foram questionados sobre o que aprendem em Geografia. A princípio esta indagação pode parecer muito subjetiva, porém, ilustra a atenção e compreensão dos estudantes sobre a metodologia das professoras em trabalhar 0 município dentro da Geografia. Das opções descritas 96 (32,8\%) marcaram que aprendem o município, 57 $(19,5 \%)$ o mundo e 121 (41,3\%) o município como parte do mundo. Ainda teve um pequeno contingente de $19(6,5 \%)$ que deixou em branco.

Havia ficado um campo em branco para sugestões, no entanto, a partir do questionamento de um estudante se poderia colocar o nome da sua rua e número da casa neste campo, foi solicitado a todas as outras turmas visitadas que no final os estudantes escrevessem o logradouro. Através deste item, podemos identificar em linhas gerais o conhecimento local do estudante. Preencheram de forma completa 234 (79,9\%) estudantes, já 34 (11,6\%) preencheram de forma incompleta ou colocaram o nome do município, bairro e 25 (8,5\%) não preencheram.

Com base nessas informações podemos constatar que no universo da pesquisa os estudantes julgam conhecer seu município, mas confundem as divisões políticas e administrativas. Também foi considerável o número de estudantes sem o domínio dos conceitos de urbano e rural. Assim, aparenta ser confuso o objetivo das aulas de Geografia, uma vez que há divisão e equilíbrio nas respostas sobre o que é estudado na disciplina. A parcela que não saberia informar o logradouro é pequena se consideramos as respostas incompletas como um conhecimento local menor.

\subsection{Análise das informações coletadas}

A maneira mais comum de ensino da Geografia tem sido pelo discurso do professor ou por intermédio do livro didático. Assim, o discurso parte de alguma noção ou conceito chave e versa sobre algum fenômeno social, cultural ou natural que é descrito e explicado, de forma descontextualizada do lugar e distante da realidade dos estudantes. Isso pode ser verificado junto às professoras, em especial quando acontece a mensuração do aprendizado. Isto é, após a exposição ou leitura, a professora avalia por exercícios de memorização se os estudantes aprenderam o conteúdo.

Em três turmas, de todas as visitadas, as professoras tinham algum mapa sempre exposto. Estes estudantes, não ficaram tão divididos como na média geral e por turma, marcaram em maioria aprender em Geografia o município ou o município como parte do mundo. Isto nos leva a crer que o mapa presente na sala de aula tem influência sobre a consolidação do conhecimento, independente da abordagem do professor.

Não é possível diferenciar as respostas dos estudantes por turnos. Das 13 turmas, 6 eram matutinas e 7 vespertinas, as respostas não podem ser classificadas segundo este critério. O mesmo vale para o tempo de serviço das professoras, bem como, formação em pedagogia ou fora. Também refutamos a ideia de que um horário pré-estabelecido e cadernos para as diferentes áreas do conhecimento, em especial um para Geografia, possa melhorar o desempenho dos estudantes.

Se por um lado existe a preferência em introduzir o estudo do município da escala mundial para a local, por outro há preferência pelo contrário, do local para o mundial. Não foi possível fazermos esta analogia. O desempenho dos estudantes foi semelhante. No entanto, Straforini (2001) buscou respostas a esta dúvida e ratifica através de Pontuschka (1999) e Callai (1998), que o ponto de partida para o ensino de Geografia nos anos iniciais é o lugar, entendido como ponto de encontro entre lógicas locais e globais, longínquas e próximas. Com isso, grifamos que o grande desafio da alfabetização 
espacial está em ler o mundo e perceber e conceber o espaço geográfico.

\section{Considerações finais}

Enquanto os livros didáticos apresentam reflexões conceituais mais complexas, e poucas sugestões de atividades práticas, os professores dos anos iniciais se esforçam para trazer o cotidiano à sala de aula. A falta de material reunido sobre o município acaba dificultando ainda mais esse desafio. Assim, com base nas sugestões das professoras entrevistadas, indicamos os seguintes itens como importantes e necessários para uma melhor construção do estudo do município:

- Atlas municipal escolar - com informações diversas e gerais do município (Importante conter mapa usos do solo, hidrografia, hipsometria, clima, transportes...).

- Mapa do município - construção de um mapa completo (Mundo, América do Sul e Brasil, Rio Grande do Sul, município, distritos, sedes de distritos).

- Material didático para os estudantes. Contendo mapa e informações gerais do município.

- Curso de atualização específico (Geografia e História) para trabalhar o município em séries iniciais direcionado a professores com formação fora da área de geografia/história - destaque para busca de dados nos indicadores do IBGE e uso da internet para atividades.

- Orientação para excursões de campo no município (pontos turísticos e distritos e sedes) - como organizar, o que é indispensável.

- Ciclo de debates, ou oficina para a troca de experiência entre estudantes de graduação (Pedagogia, História e Geografia) e professores do ensino fundamental anos iniciais.

- Um mapa do município presente na sala de aula.
- Produção técnica elaborada pela Secretaria Municipal de Planejamento ou Administração, para base de informações confiáveis referentes ao município. Reunião de referências e compêndio de textos com todo o material atual do município organizado e disponível na Secretaria Municipal de Educação para escola e professores do ensino público (estado e município) e privado.

- Formulação de livro paradidático contendo experiências e sugestões de atividades para trabalhar o município nos anos iniciais.

- Criação de um grupo de pesquisa que possibilite auxiliar na elaboração e acesso as informações municipais para as escolas.

Quanto aos estudantes, manifestaram dificuldades em discernir divisões administrativas (distritos, municípios, estado) e o rural do urbano. A presença de um mapa na sala de aula é fundamental. Num primeiro contato com a Geografia, as crianças têm de compreender o lugar onde moram, procurando estabelecer relações entre diferentes escalas espaciais e temporais. Isto é, o lugar e o estudo do município não podem ser egocêntricos e singulares, uma vez que preconizam as relações com o mundo.

O estudo do município precisa ter continuidade o Ensino Fundamental anos finais e Ensino Médio, para que diferentes aspectos sejam percebidos em diferentes momentos da escolaridade. Dessa maneira os estudantes podem construir compreensões novas e mais complexas e igualmente desenvolver a capacidade de identificar e refletir sobre diferentes aspectos da realidade.

Contudo, entendemos como necessidade urgente, por iniciativa da universidade em parceria com as secretarias municipais de educação, a constituição de um grupo de pesquisa, para a construção de documentos que possam suprir estas carências, possibilitando um estudo mais aprofundado sobre o município e ainda servir de apoio em outras situações. Assim, preenchendo uma 
lacuna presente neste momento tão importante para a Geografia (a alfabetização espacial).

Frente às carências e itens elaborados para a construção de material auxiliar, um atlas municipal escolar parece ser extremamente relevante. Todavia, com resultado mais rápido e menos oneroso a produção de um mapa trazendo diferentes escalas, do mundo a sede dos distritos e informações populacionais parece ser bastante relevante. Entretanto, mesmo que elaborado de forma gratuita, envolve custos de impressão. Neste sentido, outra possibilidade é o acesso fácil, online, as bases do IBGE. Sugerimos os seguintes bancos de dados do Portal do IBGE <www.ibge.gov.br>: "CIDADES@", "ESTADOS@” e "PAÍSES@" que apresentam informações diversas, atualizadas e oficiais, dos municípios e estados brasileiros e países do mundo.

\section{Referências}

BRASIL, Ministério da Educação. Parâmetros Curriculares Nacionais: história, geografia. Caracterização da área de Geografia. Secretaria de Educação Fundamental. - Brasília: MEC/SEF, 1997. 166p. Disponível em: $<$ http://portal.mec.gov.br/seb/arquivos/pdf/livro05 2.pdf> Acesso em: 28 mar. 2009.

BRASIL, Senado Federal. Poder Legislativo. Lei 11274 de 06/02/2006 - Lei Ordinária. Disponível em: <http://www6.senado.gov.br/sicon/ListaReferenci as. action?codigoBase $=2 \&$ codigoDocumento $=25$ 3755> Acesso em: 10 abr. 2009.

CALLAI, Helena Copetti. Aprendendo a ler o mundo: a Geografia nos anos iniciais do ensino fundamental. Cad. Cedes, Campinas, vol. 25, n. 66 , p. 227-247, maio/ago. 2005. Disponível em: <http://www.scielo.br/pdf/ccedes/v25n66/a06v25 66.pdf> Acesso em: 04 abr. 2009.

Estudar o lugar para compreender o mundo. In: CASTROGIOVANNI, Antônio Carlos.Org. Ensino de Geografia: práticas e textualizações no cotidiano. $6^{\mathrm{a}}$ edição. Porto Alegre: Medição, 2008. p. 85-135.

Geografia em sala de aula pratica e reflexões. Porto Alegre: Ed da UFRGS, 1998.
CASTROGIOVANNI, Antônio C. Apreensão e compreensão do espaço geográfico. In: CASTROGIOVANNI, Antônio Carlos.Org. Ensino de Geografia: práticas e textualizações no cotidiano. $6^{\mathrm{a}}$ edição. Porto Alegre: Medição, 2008. p. 13-83.

FEE. Resumo estatístico: municípios. 2009. Disponível em: <http://www.fee.tche.br/sitefee/pt/content/resumo /pg_municipios.php> Acesso em: 15 jul. 2016.

IBGE. Cidades@: Rio Grande do Sul, Pantano Grande, Histórico. 2009. Disponível em: <http://www.cidades.ibge.gov.br/painel/historico. php?lang $=\&$ codmun $=431395>$ Acesso em: 15 jul. 2016.

. Organização do território: Malhas municipais. $2007 . \quad$ Disponível em: <ftp://geoftp.ibge.gov.br/organizacao_do_territori o/malhas_territoriais/malhas_municipais/municipi o_2007/escala_2500mil/proj_geografica_sad69> . Acesso em: 15 jul. 2016.

PONTUSCHKA, N. N. A Geografia: pesquisa e ensino. In: Carlos, A. F. A. Novos caminhos da Geografia. São Paulo: Contexto, 1999.

SANTOS, Milton. Espaço e método. São Paulo: Nobel, 1985

SILVEIRA, Rogério Leandro Lima da. Cidade, corporação e periferia urbana: acumulação de capital e segregação espacial na (re)produção do espaço urbano. 1. ed. Santa Cruz do Sul: EDUNISC, 2003.

STRAFORINI, R. Ensinar Geografia nas séries iniciais: o desafio da totalidade mundo. 2001. 155f. Dissertação (Mestrado) - Instituto de Geociências, Universidade Estadual de Campinas, Campinas. Disponível em: <http://libdigi.unicamp.br/document/?code=vtls00 0236045> Acesso em: 25 jul. 2016.

TRIOLA, Mario F. Introdução à estatística. 7. ed. Rio de Janeiro: LTC, 1999.

VIANNA, Ilca Oliveira de. A Metodologia do Trabalho Científico: em enfoque didático da produção científica. São Paulo: EPU, 2001.

VOGT, O. P.; ROMERO, M. R. Z. (Org.). Uma luz para a história do Rio Grande: Rio Pardo 200 anos : cultura, arte e memória. Santa Cruz do Sul: Gazeta Santa Cruz, 2010. 